This is a pre-publication version of this paper. The final paper was published in Climatic Change (DOI 10.1007/s10584-015-1530-z). This article is part of a special issue on "The National Climate Assessment: Innovations in Science and Engagement" edited by Katharine Jacobs, Susanne Moser, and James Buizer.

\title{
Aspirations and common tensions: larger lessons from the third US national climate assessment
}

Susanne C. Moser 1 (corresponding author)

Jerry M. Melillo 2

Katharine L. Jacobs 3

Richard H. Moss 4

James L. Buizer 5

1 Susanne Moser Research \& Consulting, Santa Cruz, CA, USA and Woods Institute for the Environment Stanford University Palo Alto CA USA, Email promundi@susannemoser.com

2 Marine Biological Laboratory Woods Hole MA USA

3 Center for Climate Adaptation Science and Solutions; Dept. of Soil, Water and Environmental Science University of Arizona Tucson AZ USA

4 Pacific Northwest National Laboratory Joint Global Change Research Institute College Park MD USA

5 Climate Adaptation and Development, Institute of the Environment; School of Natural Resources and Environment University of Arizona Tucson AZ USA

All of the authors of this paper played leadership roles in the NCA3, and are therefore not unbiased observers.

\footnotetext{
Abstract

The Third US National Climate Assessment (NCA3) was produced by experts in response to the US Global Change Research Act of 1990. Based on lessons learned from previous domestic and international assessments, the NCA3 was designed to speak to a broad public and inform the concerns of policy- and decision-makers at different scales. The NCA3 was also intended to be the first step in an ongoing assessment process that would build the nation's capacity to respond to climate change. This concluding paper draws larger lessons from the insights gained throughout the assessment process that are of significance to future US and international assessment designers. We bring attention to process and products delivered, communication and engagement efforts, and how they contributed to the sustained assessment. Based on areas where expectations were exceeded or not fully met, we address four common tensions that all assessment designers must confront and manage: between (1) core assessment ingredients (knowledge base, institutional set-up, principled process, and the people involved), (2) national scope and subnational adaptive management information needs, (3) scope, complexity, and manageability, and (4) deliberate evaluation and ongoing learning approaches. Managing these tensions, amidst the social and political contexts in which assessments are conducted, is critical to ensure that assessments are feasible and productive, while its outcomes are perceived as credible, salient, and legitimate.
} 


\section{Introduction}

The Third US National Climate Assessment (NCA3) was produced in response to requirements of the US Global Change Research Act of 1990. While now a government document, the NCA3 report is also "owned" by its 240 plus authors and others who contributed to it (Jacobs and Buizer, this issue; Cloyd et al., this issue). Based on lessons learned from previous domestic and international assessments (NRC 2007), the NCA3 was strategically designed to speak to a broad public and address the concerns of policy- and decision-makers at various levels of government. Beyond these objectives, the NCA3 was intended to be the first step in an ongoing assessment process that would build the nation's capacity to respond to the challenges increasingly posed by climate change (Buizer et al. 2013). Whether or not these intentions and hopes will be realized will be determined by actions over the coming years and through independent evaluations of the successes and failures of the NCA3. Meanwhile, this Special Issue provides detailed inside views on how the assessment was conducted, and focuses attention on areas where significant progress has been made and others where the assessment's designers' own expectations were not fully met. Although its focus is US-specific and its design is a consequence of the political and economic circumstances that prevailed during its development, the NCA3 is a prominent example of common challenges and tensions that all assessment designers and implementers may face (e.g., NRC 2007; Clark et al. 2006). It also serves as an example of how to address them. In this final paper we identify cross-cutting lessons and synthesize some of the most salient advice from the authors across the Special Issue.

In doing so, we clearly recognize that all assessments must respond to specific legal requirements, charters, or policy questions, and that institutional and fiscal conditions will be significant factors in shaping the "art of the possible." At the same time, the design of an assessment is always motivated (or burdened) by multiple - and sometimes divergent - expectations of what it is intended to accomplish (NRC 2007). The federal advisory committee for the NCA3, the National Climate Assessment Development and Advisory Committee (NCADAC), for example, explicitly decided to go beyond the minimum task of summarizing and assessing the state-of-knowledge on climate change in order to better meet the needs of society. In the absence of a fully developed US National Climate Service (Miles et al. 2006), some NCA3 participants hoped that the assessment would fill some of the information needed in adaptive management and planning. The NCADAC also chose to build "knowledge networks" involving scientists and decision-makers who could share expertise and together identify the most critical issues for the assessment. This was intended to enhance the relevance of the NCA3, but also to build adaptive capacity across regions and sectors of the US.

The high-level lessons detailed below are selected on the basis of their wider relevance, intending to inform and inspire future assessment experimentation, both nationally and internationally.

\section{NCA3's significance to assessment designers}

Given ongoing rethinking of major international assessments, such as those conducted by the Intergovernmental Panel on Climate Change, the Intergovernmental Platform on Biodiversity and Ecosystem Services, the OECD and others, there are a number of reasons why the lessons learned from the NCA3 might interest policy-makers and assessment leaders internationally. 
First, national climate assessments are an essential foundation for adaptation and mitigation work undertaken within countries, but also serve as a foundation for international policy discussions. US federal agencies (e.g., Department of Commerce, USAID, Department of State) use such assessments to support international policy development which affect government activities beyond US borders. For example, NCA3 served (even while still in draft form) as the foundation for the most significant Executive Branch commitment to international and domestic climate action in US history. It has been explicitly cited as the scientific basis for dozens of resilience-related government efforts, including the President's Climate Action Plan (Executive Office of the President 2013).

Beyond its direct relevance to policy, NCA3 is of interest to international audiences because of the innovative approaches and strategies employed in its design and conduct. Among these innovations were its risk-management framing, the treatment of uncertainty (Moss, this issue), experimentation with the role of assessments in building capacity for adaptation (Jacobs and Buizer, this issue), the process documentation provided in a series of methodology workshops and associated assessment methodology reports, the innovative electronic delivery of the final product (Waple et al., this issue), and the development of indicators of change (Kenney et al., this issue). We do not discuss these particular innovations here again (see cited papers), but focus instead on the larger, cross-cutting lessons learned in the NCA3 below.

Due to the integrated nature of human-environmental systems, the risks and opportunities associated with climate change cascade across sectoral and international boundaries. This makes a clear-eyed assessment of risks in any country of mutual interest to those managing emissions and minimizing risks across the globe. Even climate drivers that cause direct local impacts in certain places (e.g., sea-level rise and related hazards affecting specific areas of the coast) can result in indirect ripple effects (e.g., via the insurance and reinsurance industry or international trade) in other regions, sectors, and nations (Moser and Davidson, this issue). Negative impacts on Indigenous lands and cultures are of global significance (Maldonado et al., this issue). Similarly, economic impacts due to changes in ecosystem services (Grimm et al., this issue), agricultural productivity, and so on occurring in the US will indirectly affect other countries. The converse is also true. In a globalized economy, nations are inextricably linked in myriad ways, and these linkages can be explored through assessment processes (e.g., Moser and Finzi Hart 2015). Although the NCA3 does not fully articulate the international implications of climate change on the US (Liverman, this issue), there are multiple instances where these issues are discussed in the NCA3. More fully evaluating the issue of international interdependencies is an unfilled priority that needs to be addressed in future US assessments (Buizer et al. 2013), and is a good example of the transferable research and assessment needs that every nation faces.

Given the important role assessment play in documenting where impacts are manifesting and whether mitigation and adaptation efforts are sufficient to prevent and/or limit harm, a fuller appreciation of the interaction between assessments and climate responses (e.g., Howden and Jacobs, this issue) and the need for evaluating decision-support needs and capacities (e.g., Moss, this issue) is relevant well beyond the US experience.

Furthermore, the US investment in climate science is the largest of any country globally (see annual research budgets in the "Our Changing Planet" publications at www.globalchange.gov ). Periodic efforts to integrate, analyze and evaluate the outcomes of this investment also serve as a critical contribution to 
climate knowledge for the global community. The integration of multiple kinds of knowledge - ranging from physical climate science, to social science, to tacit knowledge of resource managers - enhances the relevance of the findings of the US Global Change Research Program (USGCRP), isserves as a contribution to knowledge well beyond the US, and is of special interest to scientists and policy-makers worldwide.

Finally, an important innovation is the unprecedented degree of public engagement and transparency that permeated the NCA3 process (Cloyd et al., this issue). There was substantial perceived risk to the process itself associated with the decision to maximize engagement of many regional and sectoral experts who had never before been engaged in climate assessment processes. Though this risk was a source of concern to many and was used as a rationale for cutting back on public outreach and engagement on occasion, in retrospect, these efforts proved very successful and may actually have served as a kind of shield against unwarranted criticism for the process and the outcomes. This is an important lesson for others as they move forward in assessing climate risks and opportunities.

\section{Process, products, engagement and communications strategy, and the sustained assessment process}

The charge given to the NCADAC, which oversaw the NCA3, had two parts. The first part, as set out in the NCADAC charter, was "to synthesize and summarize the science and information pertaining to current and future impacts of climate change upon the United States." The second was "to provide advice and recommendations toward the development of an ongoing, sustainable national assessment of global change impacts and adaptation and mitigation strategies for the Nation." This two-part charge guided the work of everyone involved in the design and production of NCA3 and framed the recommendations submitted to the USGCRP regarding a sustained assessment process (Buizer et al. 2013). Here, we reflect on three core aspects of NCA3 - its process, its products, and its engagement and communication strategies - and how these aspects relate to the sustained assessment process, as a first way to synthesize insights and lessons learned from the assessment.

\subsection{Process}

Participants in the NCA3 generally agree that it was successful in building an actively engaged assessment community while also promoting engagement of stakeholders and informing decision-making. From the perspective of the authors of this article, important process successes included the internal assessment management and staffing, the consensus decision process established by the NCADAC, the structure and leadership provided by the Executive Secretariat (established to help manage the process given the 60-member NCADAC), the overall transparency of the process, the active engagement of federal agencies (in some instances significantly more than in previous assessments), the broad participation of both knowledge users and producers, and the fostering of strong regional climateassessment nodes (Cloyd et al., this issue).

Beyond the explicit focus on including new faces and multiple perspectives in leadership and author teams, the expanded role of the federal agencies in this process ${ }^{1}$ not only facilitated financial support for the assessment, but it also fostered participation of talented federal scientists with expertise in how to access and interpret information (e.g., large government-collected datasets) relevant to the assessment (Waple et al., this issue). The NCA3 also successfully built interdisciplinary author teams (including 
social scientists) and asked process experts to help facilitate effective interaction among diverse participants.

Based on discussions with NCA3 authors and stakeholders, the broad participation fostered engagement and dialogue. In a number of cases, this led to the co-production of new knowledge (e.g., in the coastal chapter; Moser and Davidson, this issue). The strong regional assessment teams supported regional and sub-regional analyses of climate impacts and geographically relevant responses, each producing peerreviewed and subsequently published "foundational documents." These teams also provided a structure from which to engage decision-makers and inform stakeholders potentially interested in climate changes, impacts, and responses.

Not all aspects of the assessment process were unqualified successes, however. Areas in which the process fell short included inconsistent deployment of the risk-based framing and the guidance on documenting degrees of certainty in the findings (Moss, this issue). Looking to the future, the framing approach and instructions about characterizing degrees of certainty must be communicated to authors early and clearly (as noted in NRC 2007), and applied consistently across all outputs produced in the sustained assessment process. In addition, while external experts had recommended including risk communication and uncertainty assessment experts on every team, the realities of timing, author selection criteria, and resources precluded this. Similarly, formal evaluation of assessment and decision-support processes was not as well integrated into the NCA3 as it could have been. Improving the dialog about decision-maker needs and useful products at all stages of the assessment process would strengthen future assessments efforts (Moss, this issue). The methodology workshops and specific training workshops for authors before assessment activities commence could be used for such capacity building.

\subsection{Products}

From the perspective of the authors of this paper, NCA3 products can be judged successful along various dimensions. They include technical reports that served as inputs to the regional and most of the sectoral chapters of the synthesis report, the highly integrated and very clearly written highlights document, and an exceptional web site. The technical reports not only helped to provide a solid foundation for the public review draft of the 2014 quadrennial report, they also contributed to achieving a major objective of the assessment - engagement of a broad set of experts and stakeholders in the process. The highlights document captured the essence of the much longer synthesis report in a way that proved very accessible to the press and played an important role in the extensive coverage of the NCA3 in newspapers (over 10,000 articles published within a year of the release of the NCA3), on radio and TV, and on new and social media. Web statistics suggest that regional chapters are of particular value to readers - most likely a reflection of people's interest in what happens in the places where they live. The overview document and the NCA3 web site have both proven to be excellent teaching tools, and are being used widely to educate and inform the public about climate change, its impacts, and possible adaptation and mitigation responses (Cloyd et al., this issue). Another successful product-related innovation was the initiation of a national indicator system, which is intended to be regularly updated to help monitor changes over time in a more consistent way (Kenney et al., this issue) .

The biggest product-related challenge came when the deadline for completion was looming. Complex parallel processing occurred at this time and involved the simultaneous production of final chapters and multiple synthesis materials, as well as the creation and deployment of the website; it proved challenging 
to do all of this while maintaining consistency across all of the products. However, these challenges were mostly overcome through the work of dedicated USGCRP and Technical Support Unit staff.

\subsection{Communication and engagement}

Internal and external communication about NCA processes and products was highly effective, thanks in part to a dedicated working group of the NCADAC that worked with USGCRP staff to develop relevant strategies early in the NCA3 effort. The assessment distinguished communication (two-way exchange about the assessment) from engagement (forms and opportunities for participation in the assessment process).

Regarding the former, the staff and technical editors' efforts to produce written documents (and associated graphics) in an accessible style and consistent voice, and the online delivery with easy links to social media, were critical elements in successful communication (Cloyd et al., this issue). Regarding the latter, the creation of the NCA network (NCAnet) was perhaps the single most innovative aspect of the NCA3. NCAnet served as one of the principal venues for engagement of outsiders with the NCA process, and continues as a "network of networks" that engages people across the US. The more than 150 NCAnet partner organizations have extended the NCA process and products to a broader audience than could have been reached otherwise. They have developed assessment-related capacities and products, hosted workshops, town halls and media events, collected and synthesized data, and produced technical and scientific information relevant to current and future NCA reports. In addition, NCAnet partners have disseminated report findings to various audiences and produced secondary products related to the NCA and NCA findings. For example, the National Council for Science Education supports an education affinity group within NCAnet that has produced curricula, webinars and other training sessions based on NCA3 content. Further, NCAnet partners helped produce - for the first time - a summary of NCA3 findings in Spanish for the 50+ million Americans who speak Spanish in their homes daily.

A major challenge in communication involved the management of expectations of the public after the public review period, but before the release of the completed report. Thirteen months elapsed between the close of the public review period and issuing the final NCA3. During this time, four important activities occurred: (1) revisions of the public review draft in response to comments; (2) evaluation by review editors of the degree to which the revisions were responsive to the public review comments; (3) several rounds of technical review of the revised NCA3 drafts by scientists at USGCRP agencies and at the Office of Science Technology Policy; and (4) signoff by report authors, and subsequently the NCADAC, on the final draft of the report. The public was interested in following progress of the process and could do so in a general way, but did not get to see each iteration. Carefully managing the need for transparency and legitimacy and the need for efficient completion of the full report without undermining its credibility or its salience was a challenge in the NCA3 and is an issue for all large-scale assessments.

\subsection{Sustained assessment process}

The NCA3's overarching goal of establishing a highly credible, ongoing assessment process was linked to three sub-goals: building a foundation of engagement with assessment partners, creating easily understandable and accessible products that can be updated on an ongoing basis, and ensuring transparency and testing effective assessment processes. Details of how to best implement this set of goals are still evolving within the USGCRP and are guided, in part, by a special report produced by the 
NCADAC, Preparing the Nation for Change: Building a Sustained National Climate Assessment Process (Buizer et al. 2013). Some recommendations have already moved from idea to action (Buizer et al., this issue). For example, targeted topical assessments were suggested that meet user- or expert-identified information needs and can serve as inputs into subsequent quadrennial reports. The first of these targeted reports, entitled The Impacts of Climate Change on Human Health in the United States: A Scientific Assessment, is being completed at the time of this writing. A USGCRP Indicators Initiative (Kenney et al., this issue) is now in a pilot phase. Workshops have been held on the development of land use/land cover and population scenarios for use at sub-national scales. Additionally, the preparation of usable climate scenarios is being discussed.

Other topics and recommendations appear to be lagging. Of greatest concern is that the focus of activity remains almost exclusively on the production of reports coordinated through federal agencies. The special report's recommendations to move toward a wider range of NCA products such as data sets, scenario planning methods, tools for vulnerability assessments, maps, and others, and to make a more concerted effort at addressing the international dimension have not yet been realized. The recommendation to encourage a distributed assessment approach, allowing for a series of self-motivated assessment processes organized by municipalities, sectoral interest groups, universities, NGOs and other interested parties does not seem to have progressed. The recommendation to appoint a smaller advisory committee with expertise appropriate for assisting with the transition to a sustained process is still in early stages at the time of this writing. Steps to evaluate and improve approaches for characterizing uncertainty and communicating confidence do not appear to have been taken. The apparent lack of progress in some of these areas is of concern since the clock is ticking toward the 2018 quadrennial report.

\section{Common tensions requiring management in effective assessments}

In the course of NCA3, we encountered a number of tensions related to diverging expectations about process, products and outcomes, information needs, available resources, size and complexity of the effort, and other issues. These tensions emerged in discussions about how to build a workable structure for an effective assessment, how to choose topics at scales that are most useful given the wide range of possible approaches, how to ensure efficient outcomes and processes that are consistent with agreed-upon goals for an assessment, how to agree on priorities across multiple expectations of what assessments ought to achieve, and how to critically, but constructively, learn from ongoing assessment efforts so as to continually improve them. These are challenges all assessment designers and leaders face.

Perspective gained on these topics during the NCA3 may be useful to other assessment processes and are offered here as another way to extract larger lessons from the contributions in this Special Issue. The tensions and trade-offs are sometimes more perceived than real, but difficult choices clearly have to be made in any assessment. Below we describe issues and choices made in the NCA3. The effectiveness of future assessments may hinge on how these tensions are managed given place- and time-specific circumstances.

\subsection{Tension among core assessment ingredients}

Previous studies focused on the tension between "product" and "process" in shaping assessments (e.g., Morgan et al. 2005; Clark et al. 2006; NRC 2007). This framing brought central attention to the outputs of an assessment and how those co-determine the most important qualities that assessment participants and 
observers aspire to: salience, credibility and legitimacy (Cash et al. 2003). Together, these qualities affect the overall effectiveness of an assessment in terms of informing policy and decision-making. What the product-process dichotomy hides are the principal ingredients that enable particular products and processes to be delivered. In the interest of informing future assessment designs, however, it is useful to focus on those essential ingredients, and thus deepen the understanding of qualities that render some assessments more effective than others. Such a deeper look brings attention to the inside workings of assessments, i.e., to the underpinnings that allow products and processes (Section 3 ) to be delivered.

Based on our experience from multiple assessment processes, four ingredients are critical to success: (i) the information, data, scientific studies, situational knowledge (of real world problems, geography, systems or decision contexts), and other kinds of traditional knowledge that form the knowledge base of the assessment; (ii) the institutions and resources to conduct an assessment (reflecting legal support, legacies of other processes and reports, financial and staff resources, political will and commitment); (iii) principles and approaches that guide participants; and (iv) the people/human capital required to carry it out (Fig. 1). We view each of these as necessary but - by themselves - insufficient ingredients that enable an assessment to deliver products and processes that eventually are perceived as credible, salient, and legitimate. While there is some degree of mutual compensation across these four essential ingredients (dedicated people can make up, to some extent, what money could buy if it were available; a principled process can compensate for some institutional inadequacies), assessment designers cannot ignore any of these four essential ingredients unless they are willing to risk the success of the whole operation. These core ingredients, to whatever extent available, must be aligned so that all assessment participants and sponsors come - through the course of ongoing communication, dialogue and negotiation - to hold a shared understanding of and agree to:

- the mandate and expectations about outcomes and products, including an understanding about who the likely assessment users will be and how they might use its products;

- the rules of engagement, standards of procedure, and legal/institutional requirements;

- the identification and roles of different players, including leaders, technical experts, intermediaries to help with interpretation and communication, editors, reviewers, graphic artists and policy- or decision-making communities with the capacity to engage in the process and apply the knowledge generated; and

- the logistical constraints (timing, fiscal) that affect what can be done. 
Figure 1: The art of the possible: Careful alignment of core assessment elements ingredients ensures an effective assessment operation. Source: The authors

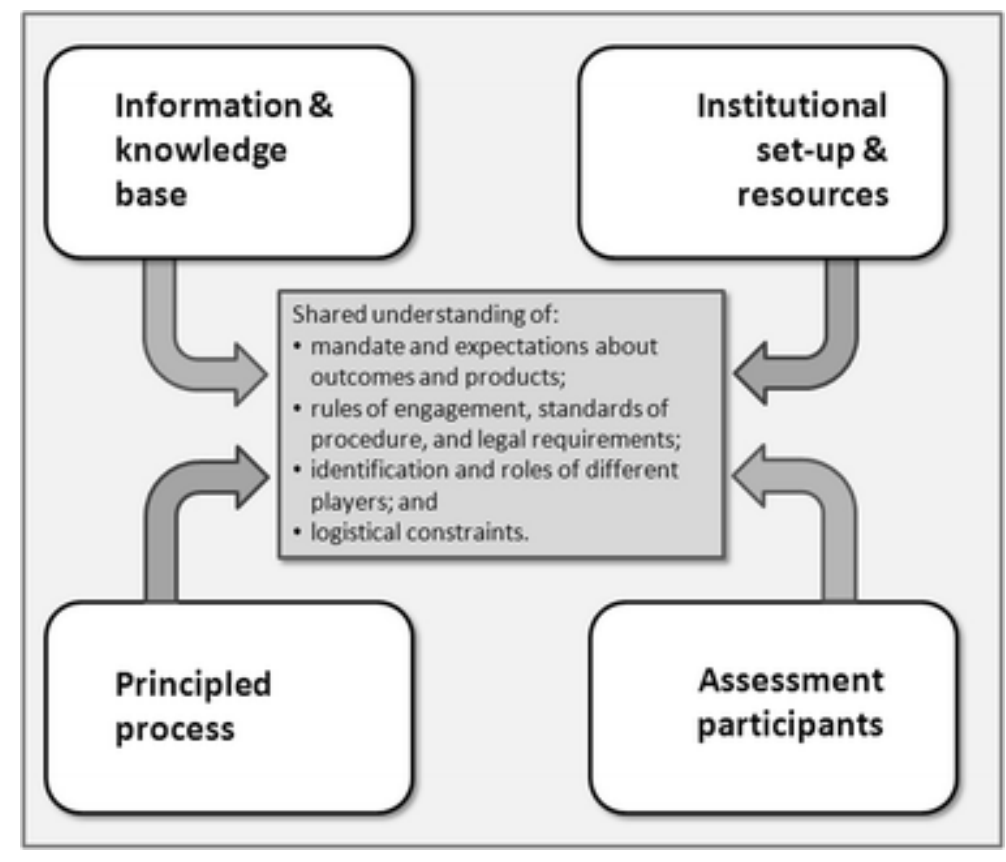

How were the tensions among these four core ingredients handled in NCA3? First, much attention was paid to the knowledge foundation. Clearly, every decision made about the information base affects its perceived salience, credibility, and legitimacy. For example, the quality and accessibility of underlying data to foster transparency and utility of the final product were important foci. Similarly, a widely recognized strength of NCA3 was the organization and presentation of observations of climate changes at various spatial scales, from global, to national, to regional. Rigorous scientific procedures and criteria were used to attribute specific impacts to climate change vs. other drivers of change at each of these scales. Another example is the openness with which, in the early days of the NCA3, a number of important questions were discussed and resolved between the authors and the NCADAC, adding to its ultimate credibility and salience, e.g.,: Which climate change scenarios should be used so as to recognize the state of the science and be compatible with IPCC, yet also provide information at the right scale and resolution for every region of the US? To what extent should the state of physical climate science dictate which ecological and social impacts science can be used? How should non-peer-reviewed information be handled, i.e., what is a principled and defensible approach to quality assurance? How do we track, inventory, store, and make available and accessible all the information that went into the production of the NCA3? And finally, what delivery mechanisms and product formats are most useful to citizens and decision-makers?

Clarity about rules and procedures as well as about the roles and responsibilities of different assessment participants - the second and third core ingredients - was critically important. For example, extensive effort was put into designing an assessment process that built on past experience with other assessments, took advantage of the best available methodological approaches (process and methods workshops), but also was feasible in the current political and economic context within the US. Assessment leaders, sponsoring agencies and the NCADAC deliberated on: How much engagement is useful, desirable, 
necessary, affordable, and feasible? What are the best engagement and communication approaches? How can federal agency needs and capacities be balanced with external stakeholder desires and capacities? How much can be asked of volunteers? How can ongoing evaluation and learning be ensured without endangering timely progress and support from all involved?

The NCA3 was sponsored by various agencies, each with particular rules and procedures. Given these, federal partners had to fulfill the letter of the law, while also experimenting with new approaches to better serve the American public. This raised continuous questions and - over the course of several fiscal cycles - required renegotiation of what is prudent and possible within institutional and fiscal constraints. This careful balancing act needs to be explicitly discussed (to the extent feasible) so that all parties recognize why certain process management decisions are necessary.

In the end, what was possible within this set of questions and constraints came down to the people doing the work - the fourth core ingredient. The NCADAC understood that it is far more than scientific expertise that makes an assessment work, although that is crucial for credibility. Involvement of those with deep expertise in policy circles and management could help make the assessment more salient and legitimate in the eyes of the public and policy-makers. Leadership skills in the NCA Coordination Office, the NCADAC, its working groups, within author teams, and among staff were absolutely essential: commitment (by everyone, paid or unpaid), determination and creativity in working around obstacles, openness to input, decisiveness, and motivation to move the process forward, the ability to stay organized and engaged with 30 chapter teams moving forward simultaneously, and so much more. These "people skills" were decisive in delivering a salient, timely product. At the same time, considerable effort went into building social capital among all involved: within the NCA Coordination Office, within the NCADAC and its working groups, within author teams, and among the extended "NCA family" (e.g., NCAnet). With a very tight budget and a largely voluntary effort, the importance of investments in people and relationships cannot be overestimated.

\subsection{Tension between national scope and Sub-national adaptive management information needs}

As the NCA seeks to become increasingly relevant to adaptation and emissions reduction efforts, the tension between providing information at national and more local scales will increase. Users involved in adaptive management and planning expect to receive information tailored to their location, decision or question, but available models and data sources are often not yet up to this task. Information at the national or regional scale can be helpful in framing challenges or providing a broad context, but may be too coarse to inform certain decisions. In addition, decision support for planning or managing specific adaptation and mitigation efforts will necessarily entail more user support and engagement, leaning towards "climate services." It seems unlikely that a centralized national assessment will ever have sufficient resources to provide a comprehensive climate services portfolio to meet local needs. Thus assessments will need to balance user expectations about fulfilling information needs with what is technologically possible and scientifically defensible. Galford et al. (this issue), explore the lessons learned in a state-scale version of a climate assessment, providing insights useful in this regard.

One possible extension of traditional assessments, however, and thus one way to better translate between what is scientifically defensible and practically desirable, is for the sustained assessment process to not just focus on comprehensive national reports and periodic topically-targeted reports, but also on critically assessing the use and value for specific purposes of commonly available data, methods, visualizations, 
and other tools and resources. An assessment cannot provide decision support systems tailored to individual decision-making environments and situations, but it can add value by producing credible and useful outputs with wide applicability. It can also help assessment designers and users to better understand and reflect on the respective roles and relationships of national and sub-national assessments, including a clearer division of labor among public and private entities providing climate services. In addition, it can synthesize knowledge about effective decision support, evaluate different types of systems, and provide good practice guidelines (Moss, this issue).

Another approach that emphasizes the role of assessments in promoting dialog between decision-makers and the research community is to explore information needs and available products to meet those needs. Users often request specific products or methods (such as downscaling), when in fact, upon reflection with decision-support experts, it becomes clear that other products or methods would yield more useful results (e.g., summaries of statistical analysis of large ensemble data sets may provide the needed information with higher confidence than downscaling). Another useful approach could be to develop a typology of decision-making situations and information, and to accrue a repertoire of data and methods that can be adapted for similar applications. It is not that national-scale assessments are unable to meet the need for tailored knowledge; they simply cannot cover all needs at once, and must develop strategies for managing the tension between being nationally comprehensive and providing information that is detailed enough to meet adaptation and mitigation decision-making needs at sub-national-to-local scales.

\subsection{Tension between scope, complexity, and manageability}

There are benefits to creating NCA syntheses through an inclusive process, involving a large number of people. The NCA3 process involved a 60-members NCADAC, more than 240 authors, and around 1,000 additional contributors to underlying foundational and technical input documents. To some, this seemed excessive - but the benefits of broad engagement were visible throughout the process.

Participants noted the richness of experience brought by the wide array of authors, the capacity to deal with diverse process and topical issues, and especially the virtues of a distributed network that could be mobilized for different events. Having such a large and diverse team meant it was relatively easy to engage people in local areas and sectors during the report release and subsequent outreach. However, federal agencies were legitimately concerned about the cost and complexity of such extensive participation throughout the process, and whether this level of effort could be sustained. $\stackrel{2}{\text { Even with a }}$ mostly volunteer "army" working on the report, the costs associated with managing the process must be acknowledged and objectively evaluated relative to the benefits.

As described in more detail in other contributions to this Special Issue (Jacobs and Buizer, this issue; Cloyd et al., this issue), the three completed national assessments took different approaches in this regard. The first NCA (NCA1) shared with NCA3 an emphasis on engagement in which stakeholders provided input about their information needs and learned from scientists about climate change. This direct engagement in NCA1 raised expectations among stakeholders of further engagement, and then lead to disappointment because no resources were available to sustain these nascent relationships.

The second NCA (NCA2) was efficient and produced a credible document, but - based on the very limited press coverage relating to NCA2 and feedback received from a wide range of participants in NCA3-related events - failed to reach the American public in a meaningful and sustained way. The 
tension here is between the benefits of big vs. small synthesis efforts, and the benefits of an easily managed process vs. the benefits of a broad engagement strategy. In the NCA3, assessment leaders took the more engaged, if more complex, approach in light of growing stakeholder expectations and needs for salient information to inform mitigation and adaptation efforts.

As described in Buizer et al. (2013), multiple advantages can be derived from a highly strategic and wellmanaged sustained assessment process. From the perspective of conserving resources at the federal level, a key benefit of a more distributed process (in which self-motivated users work with data, products, and tools) is that it shifts some of the assessment burden on to intermediaries (e.g., in the NGO or private sectors) and entities conducting their own assessments. This helps to avoid burn-out of the relevant expert community and increases the human capital for doing assessments (i.e., the core ingredient of "people"), and improves the quality and utility of assessment products. A sustained assessment thus must: (1) retain (and enhance) value, utility, transparency, and credibility; (2) serve information needs of decision-makers at multiple scales, i.e., develop salient climate information; and (3) build an ongoing, manageable and legitimate process. Clearly, there will be a need to engage partners outside of government to achieve these goals, given the significant limitation on government resources.

A critical concern about reducing the overall size of the NCA effort is the need to ensure that a federal advisory committee (required when there is ongoing engagement of non-governmental participants in government processes) is constituted in a way that optimizes the utility of assessment outcomes, while adequately representing regional and sectoral interests. This is significantly more challenging than assessing physical climate changes. This tension between inclusiveness and efficiency needs to be addressed to ensure that the process supports the goals of the sponsoring program (in this case, the USGCRP) as well as the broader public interest.

Generating enthusiasm for smaller, targeted assessment products (even though those might go into greater depth, provide input to the national assessments, or fill specific knowledge gaps) may be harder than getting people engaged in a big, highly visible national effort every 4 years. In aggregate, multiple shorter, targeted products and synthesis reports could even be more expensive than the NCA3 approach if not carefully managed. On the other hand, there are substantial benefits and satisfaction from meeting user needs. The attraction of working on a national assessment that would become the foundational scientific document for executive branch activities was a significant incentive for the authors of the NCA3. How can a more distributed, ongoing and evenly-paced process generate the same level of commitment? This will be a significant challenge, given that resources will be needed from both federal and non-federal participants. Assessments can certainly be done more cheaply, but getting useful outcomes per dollar spent is really the goal.

If a sustained process can be implemented quickly, a "bottom up" meets "top down" sustained assessment approach that involves external partners with regional and sectoral teams and incorporates a federal structure and management team seems like an obvious next step based on the lessons learned and capacity built during the NCA3. Building from this capacity to a long-term approach that facilitates contributions from external parties within a federal framework will help to match resources with expectations.

\subsection{Tension between deliberate evaluation and ongoing learning approaches}


The NCA3 leadership decided from the start to build ongoing monitoring and evaluation into its operations. This was not only evident in its strategic plan and the transparency and effectiveness goals, but also by making the framing and approach to "evaluation" an explicit assignment of a NCADAC Working Group..$^{-}$At first, the whole idea of evaluation was resisted, in part because evaluation was seen as a task separate from assessing the science and delivering a report, and in part because it was interpreted as passing judgment on performance, which could backfire and undermine agency and funding support for the entire enterprise, or open the door to public criticism.

This led the evaluation working group to suggest framing the NCA as a "learning organization," and make evaluation an ongoing and useful tool to enable participants to make course corrections as needed. In addition, mechanisms were established to track activities, outputs, impacts, and to collect feedback during regional town halls and other workshops. These formal tracking mechanisms and other informal mechanisms including "reflection time" during NCADAC meetings (and its Executive Secretariat) and NCA staff meetings, fostered flexibility and learning internally. For example, a staff-led analysis of media coverage after the release of the public review draft helped support the rollout strategy and provided encouraging feedback to the authors and NCAnet, further building social capital among volunteer partners. After the completion of the NCA3, the sponsoring agency (NOAA) also administered a short survey to NCADAC members on the experience of participating in the assessment for its own internal purposes and then USGCRP supported a process workshop focused on lessons learned in the NCA3. At the workshop evaluation experts and participants came to general agreement on what an external evaluation could accomplish and how it could be conducted (USGCRP 2014), but as yet no funding has emerged to support a formal external evaluation. It is unclear whether federal agencies will see the potential value of such evaluations as part of the sustained assessment process to be greater than the potential risks, or whether a foundation or research funding agency will have enough interest to support such an effort.

Thus, the tension over when or how to build monitoring and evaluation into assessment processes has remained focused on internal, ongoing, learning-oriented mechanisms. Our experience shows that this is an absolute necessity. But without external, independent eyes, future assessment designers lack an essential feedback mechanism. We view this as a critical opportunity missed that could result in less efficient future investments in assessment activities.

\section{Conclusions}

The design and conduct of assessments always involves tensions between what is scientifically defensible and practically feasible. Assessments can - if done well - have important policy, economic, and regulatory implications while providing important milestones for the scientific community. These contexts and tensions need to be explicitly recognized and managed in order to ensure that the internal management and conduct of assessments are feasible and productive, while the process and its outputs and outcomes are perceived as credible, salient, and legitimate. The widespread frustration among climate scientists and citizens associated with the inability of the US federal government and previous administrations to effectively address the causes and effects of climate change is probably one key explanation for the strong interest among NCA3 participants and contributors in volunteering to assist in the process. The groundswell of support for this effort crossed sectors and regions and included people 
from many walks of life, and formed the foundation for further engagement in a sustained assessment process.

The enormous investments of time, money, and human capital made in the NCA3 resulted in considerable good will, great appreciation by both insiders and outsiders of the process and products, and in significant growth in multi-disciplinary, interdisciplinary, and transdisciplinary networks of experts and assessment users. These, to us, provide a foundation and opportunity for the sustained assessment that is too good to lose. Ideally, the energy in the underlying tensions discussed here and prevalent in every assessment, if properly recognized and managed, can be harvested in strategic ways to increase learning and greater engagement of experts and users at all levels. The intent of this concluding paper, and indeed of this Special Issue, has been to articulate some of the tensions and lessons learned so that future assessment processes can launch from this fundamental understanding rather than having to re-learn these same lessons.

\section{References}

Buizer JL, Dow K, Black ME, Jacobs KL, Waple A, et al. Building a sustained climate assessment process. Climatic Change, this issue, DOI 10.1007/s10584-015-1501-4

Buizer JL, Fleming P, Hays SL, Dow K, Field CB, Gustafson D, Luers A, Moss RH (2013) Report on preparing the nation for change: building a sustained national climate assessment process, national climate assessment and development advisory committee, Washington, DC

Cash DW, Clark WC, Alcock F, Dickson NM, Eckley N, Guston DH, Jäger J, Mitchell RB (2003)

Knowledge systems for sustainable development. Proc Natl Acad Sci U S A 100:8086-8091

Clark WC, Mitchell RB, Cash DW (2006) Evaluating the influence of global environmental assessments. In: Mitchell RB, Clark WC, Cash DW, Dickson N (eds) Global environmental assessments: information and influence. The MIT Press, Cambridge, MA, pp 1-28

Cloyd ET, Moser SC, Maibach EW, Maldonado JK, Chen T. Engagement in the third US national climate assessment: commitment, capacity, and communication for impact. Climatic Change, this issue, in revision

Executive Office of the President (2013) President's climate action plan. June 2013

Galford GL, Betts AK, Carlson S, Ford S, Hoogenboom A, et al. Opportunities and strategies for statelevel climate assessments. Climatic Change, this issue, in review

Global Change Research Program (USGCRP) (2014) Frameworks for evaluating the national climate assessment: workshop report. USGCRP, Washington, DC

Grimm N, Groffman PM, Staudinger MD, Tallis, H. Climate change impacts on ecosystems and ecosystem services in the United States: Process and prospects for sustained assessment. Climatic Change, this issue, in revision

Jacobs KL, Buizer JL. Building community, credibility and knowledge: the third US National Climate Assessment. Climatic Change, this issue, DOI 10.1007/s10584-015-1445-8 
Kenney, MA and Janetos AC. Building an integrated national climate indicator system, Climatic Change, this issue, in revision

Liverman D. U.S. national climate assessment gaps and research needs: overview, the economy and the international context. Climatic Change, this issue, DOI 10.1007/s10584-015-1464-5

Maldonado JK, Bull Bennett TM, Chief K, Cochran P, Cozzetto K, et al. Engagement with indigenous peoples and honoring traditional ecological knowledge, Climatic Change, this issue, in press

Miles EL, Snover AK, Whitely Binder LC, Sarachik ES, Mote PW, Mantua N (2006) An approach to designing a national climate service. Proc Natl Acad Sci U S A 103:19616-19623

Morgan MG, Cantor R, Clark WC, Fisher A, Jacoby HD, Janetos AC, Kinzig AP, Melillo J, Street RB, Wilbanks TJ (2005) Learning from the U.S. national assessment of climate change impacts. Environ Sci Technol 39(23):9023-9032

Moser SC, Davidson MA. The third national climate assessment's coastal chapter: the making of an integrated assessment. Climatic Change, this issue, DOI 10.1007/s10584-015-1512-1

Moser SC, Finzi Hart J (2015) The long arm of climate change: exploring climate change impacts via teleconnections. Clim Chang 129(1-2):13-26

Moss RH. Assessing decision support systems and levels of confidence to narrow the climate Information "usability gap". Climatic Change, this issue, in revision

National Research Council (NRC) (2007) Analysis of global change assessments: lessons learned. National Academies Press, Washington, DC

Waple AM, Champion SM, Kunkel KE, Tilmes C. Innovations in information management and access for assessments. Climatic Change, this issue, in revision

\section{Notes}

${ }^{1}$ Each federal agency was represented by an ex officio member on the NCADAC.

$\stackrel{2}{2}$ For the NCA3, NOAA paid for federal advisory committee activities, some author travel, and the NCA technical support unit from a budget line established for this purpose by the Office of Management and Budget, but many other USGCRP agencies contributed staff and resources.

3 Because the evaluation task was later determined to be too large to be included in the work of the Engagement and Communication working group, the evaluation task was transferred to the working group focused on developing recommendations for the sustained assessment process. 